\title{
Correspondence
}

\section{Scientific Censorship}

SIR,--Recently we submitted a paper to a leading chemical journal in Czcchoslovakia-Collection of Czechoslovak Chemical Communications. The whole work described in our paper was performed at the Institute of Organic Chemistry and Biochemistry, Czechoslovak Academy of Sciences, Prague, between 1967 and 1969. We felt it our obvious duty to publish our paper in the journal where most of our previous papers had appeared. Moreover, our work was done exelusively on Czechoslovak territory and completely funded by the Czechoslovak Academy of Sciences.

We have been informed that in view of the publishing policy adopted by the present Czechoslovak authorities, which prohibits Czechoslovak authors who are currently living abroad without the approval of the Czechoslovak government from publishing in the Czechoslovak journal, our paper cannot be accepted for publication.

We would like to point out that the submitted paper deals exclusively with problems of the natural sciences without any relation to the present political situation in Czechoslovakia. The decision of the Czechoslovak authorities can hardly be labelled otherwise than as a diserimination of scientific work.

$$
\text { Yours faithfully, }
$$

Michigan Cancer Foundation,

$$
\text { JiRI ZEMLICKA }
$$

4811 John R Street,

Detroit, Michigan 48201 .

Stanislav Chladek

Department of Biochemistry and Biophysics,

Texas $\mathbf{A}$ and $\mathbf{M}$ University,

College Station,

Texas 77843 .

\section{Medvedev's Complaint}

Sir,-Bikerman (Nature, 228, 297; 1970) has offered a completely misleading analogy between the refusal of the National Science Foundation to supply travel funds for his trip to France, and the refusal of the Soviet government to permit Zhorez (that is not Jaurès) Medvedev to attend a Ciba Symposium. In Medvedev's case, authorization to leave the country was adamantly denied, although travel funds were actually available. Presumably Bikerman, as a naturalized US citizen, would have had no trouble in obtaining a visa to enter France.

Bikerman says that the excerpt from Medvedev's book strikes him as subtle communist propaganda. Since Medvedev, for publishing a book exposing Lysenkoism and advocating international cooperation in science has (i) lost his job, (ii) been prevented from moving to another district to look for a new position, (iii) been hauled off forcibly to a "psychiatric" institution, the way of a subtle propagandist would seem to be a steep and thorny road.

$$
\text { Yours faithfully, }
$$

Thomas H. Jukes

University of California,

Berkeley, California 94720.

\section{Definition of Intelligence}

SrR,-H. A. Fatmi and R. W. Young (Nature, 228, 97; 1970) propose a definition of intelligence for use in drawing distinctions between machine and human behaviour. They base their definition on the ability of the system to perceive order in a situation previously considered to be disordered.

While this definition is valid within extromely narrow constraints, it has serious limitations in defining the difference between men and machines. In the first place it excludes many aspects of intelligence which are of the greatest interest from a human point of view, namely, the relation between set theory on the one hand and the ability of intelligent systems not only to perceive but also to generate and choose new structures and instruction sets and ascribe meaning to both internal states and input sets.

A single machine with a finite phrase-structure grammar would not be able to realize the extended definition of intelligence given above. An extension of Fatmi and Young's definition allows us to include the missing elements on the human side of the equation.

"Intelligence is that faculty, of mind, by which order is perceived in a situation previously considered to be disordered, and whercby similar structures can be generated, recognized and scmantically defined without the necessity of complete a priori specification."

This revised definition permits the inclusion of linguistic competence, as defined by Chomsky, as an aspect of intelligent behaviour, which it certainly is. In the trivial case, we know that the child produces valid grammatical sentences in the absence of a complete instruction set. On a deeper level we also know that the set of valid grammatical statements is an infinite set and that the instruction set for a natural language cannot be completely specified. By Fatmi and Young's argument all linguistic behaviour is only apparently intelligent or, in the trivial case, we would have to assume that the same sentence uttered by a child or a parent or teacher would be sometimes a sign of intelligent and sometimes a sign of intelligence-like behaviour.

My own work leads me to the view that attempts to relate simplicistic finite set theory and automata to faculties of mind and the mechanisms of the brain inevitably leads to such difficulties. I suggest that the brain should be seen as a transfinite automaton, which cannot be defined by restricted set theory (ZF), but only by extended set theory including the all important "axiom of choice" 1 1-3.

$$
\text { Yours faithfully, }
$$
GORDON HYDE

11 The Close,

Dunmow, Essex, CM6 1EW.

${ }^{1}$ Lofgren, L., Explicability of Sets and Transfinite Automata in Automata Theory (edit. by Caianello, E. R.) (Academic Press, 1966).

${ }^{2}$ (ohen, P. J., Set Theory and the Comtinuum Hypothesis (W. A. Benjamin, New York, 1966)

${ }^{3}$ Cohen, P. J., and Hersh, R., Sci. Amer., 216, 107 (1967).

\section{Decimal Lakh}

SIR,--As the day of formal and wide acceptance of the decimal system draws closer, may I make a public request in favour of an Indian unit?

It is Laksha, writton in English as Lakh, standing for 100,000 . Surely, a lakh is a better way of saying one hundred thousand.

$$
\text { Yours faithfully, }
$$

Department of Mechanical Engineering,

$$
\text { S. RoY }
$$

University of Aston,

Birmingham 4. 